\title{
Okul Öncesi Öğretmen Adaylarının Eğitimde Teknoloji Kullanımına Yönelik Kaygılarının Bazı Değișkenlere Göre Incelenmesi
}

\author{
Bahar GÜMRÜKÇÜ BiLGiCi', Naim ÜNVER²
}

\begin{abstract}
Öz: Çalışmada okul öncesi öğretmen adaylarının eğitimde teknoloji kullanımı ile ilgili kaygılarını incelemek amaçlanmıştır. Çalışmaya 67 farklı üniversitede öğrenim gören veya mezun olan 510’u kadın, 39'u erkek olmak üzere toplam 549 okul öncesi öğretmen adayı katılmıştır. Veri toplama araçları olarak Genel Bilgi Formu ve Eğitim Teknolojileri Kullanımı Kaygı Ölçeği kullanılmıştır. Araştırmanın sonuçlarına göre okul öncesi öğretmen adaylarının eğitim teknolojisi kullanım kaygıları cinsiyet ve öğrenim gördüğü üniversite türüne göre farklılık göstermemektedir. Mezun okul öncesi öğretmen adaylarının teknoloji yönetimi merkezli kaygıları, birinci sınıfta öğrenim gören adaylara göre daha yüksektir. Yine mezun okul öncesi öğretmen adaylarının teknik merkezli kaygıları ise birinci ve ikinci sınıfta öğrenim gören adaylara göre daha yüksektir. Kişisel bilgisayar sahibi olan okul öncesi öğretmen adaylarının teknoloji yönetimi merkezli ve teknik merkezli kaygıları, bilgisayar sahibi olmayan adaylara göre daha fazladır. Son olarak okul öncesi öğretmen adaylarının yaşı ilerledikçe teknik merkezli, teknoloji yönetimi merkezli ve teknoloji-entegrasyonu merkezli kaygıları da artmaktadır. Araştırma sonuçlarını göz önünde bulundurarak, okul öncesi öğretmen adaylarının eğitimde teknoloji kullanımına yönelik kaygılarını azaltabilmek için teknik donanım ve teknoloji bilgilerinin artırılması önerilmektedir.
\end{abstract}

Anahtar Sözcükler: Eğitimsel teknoloji, Okul öncesi öğretmen adayı, Kayg1

\section{Investigation of Preschool Teacher Candidates' Anxiety About Use of Technologies in Education According to Some Variables}

\begin{abstract}
In this study, it is aimed to examine the anxiety of preschool teacher candidates about the use of technology in education. A total of 549 preschool teacher candidates, including 510 females and 39 males, who study or graduated from 67 different universities, took part in the study. As data collection tools, General Information Form and Educational Technologies Anxiety Scale were used. According to the results of the study, preschool teacher candidates' educational technologies anxiety does not differ in terms of gender and the type of university they study. The technology management-centered anxiety of graduate preschool teacher candidates is higher than the preschool teacher candidates who are studying in the first grade. Again, the technical-centered anxiety of graduate preschool teacher candidates is higher than the preschool teacher candidates studying in the first and second grade. Preschool teacher candidates who have personal computers have more technology management-centered and technique-centered anxieties than preschool teacher candidates who do not have a personal computer. Finally, as the age of preschool teacher candidates increases, technique-centered, technology-managementcentered and technology-integration-centered anxieties also increase. Considering the results of the study, it is recommended to increase knowledge about the technical equipment and technology in order to reduce pre-school teacher candidates' anxiety about the use of technology in education.
\end{abstract}

Keywords: Educational technologies, Preschool teacher candidates, Anxiety

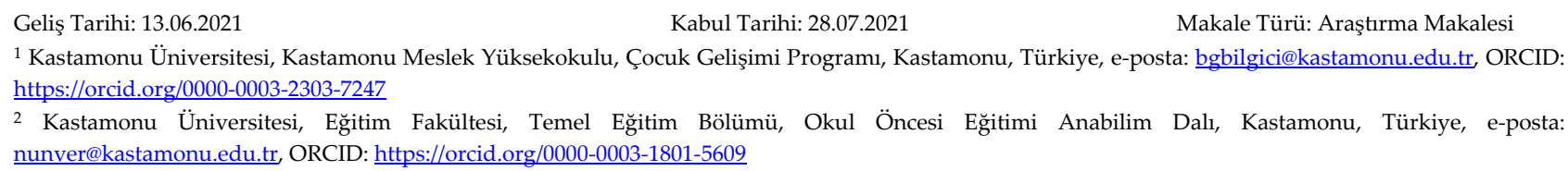

${ }^{1}$ Kastamonu Üniversitesi, Kastamonu Meslek Yüksekokulu, Çocuk Gelişimi Programı, Kastamonu, Türkiye, e-posta: bgbilgici@kastamonu.edu.tr, ORCID: https://orcid.org/0000-0003-2303-7247

2 Kastamonu Üniversitesi, Eğitim Fakültesi, Temel Eğitim Bölümü, Okul Öncesi Eğitimi Anabilim Dalı, Kastamonu, Türkiye, e-posta: nunver@kastamonu.edu.tr, ORCID: https://orcid.org/0000-0003-1801-5609 
Bilgi ve iletişim teknolojisi günümüzde çocukların içine çekildiği bir yaşam biçimi haline gelmiştir. Günümüz çocukları okulda öğrenme ihtiyaçlarını karşılayabilmek için küçük yaşlarda dijital araçları kullanmaya başlamaktadır. Eğitimsel teknoloji, eğitim sürecindeki iki temel faktör olan pratik ve aktif katılıma gereksinim duyan, teknoloji ve eğitimi bağdaştıran, öğrencilere aktarılacak öğrenme içeriğidir (Murati ve Ceka, 2017). Magen Nagar ve Shonfeld (2018)'e göre teknolojiye yönelik tutumların üç yönü vardır. Bu tutumlar teknolojik kayg1, teknolojik özgüven ve teknolojik beğenmedir. Teknolojinin bir diğer değerli rolü, öğretmenlerin dersleri organize etme ve sunma konusundaki etkililiğini artırmasıdır. Öğrencilerin bilgisayarlardan nasıl öğrendiklerine dair çok sayıda araştırma olsa da öğrencilerin bilgisayarla öğrenmesine ilişkin bilimsel bilgi ve verileri elde etmeye günümüzde daha çok ihtiyaç vardır (Ross, Morrison ve Lowther, 2010).

Günümüzde eğitimde teknoloji kullanımı internet erişimi, uzaktan eğitim, eğitici oyun ve simülasyon gibi uygulamalar ile katlanarak artmaktadır (Ross ve diğerleri, 2010). Teknolojinin eğitimdeki rolü ve önemi her geçen gün artarken tüm dünyayı etkisi altına alan pandemi sürecinde bu rol daha önemli hale gelmiştir. Görev yapan mevcut öğretmenlerin çoğunluğu X kuşağına (1965 - 1977 doğumlu) ya da Y kuşağına (1979 - 1989) (Veloso, Dutra ve Nakata, 2016) mensup iken öğretmen adayları Y kuşağına ve Z kuşağına (1990 - 2010 doğumlu), eğitim verdikleri ya da verecekleri okul öncesi dönem çocukları ise alfa kuşağına mensuptur. Teknolojik ilerleme sayesinde kuşaklar arası sürelerin bu kadar kısaldığı günümüzde, kuşkusuz her yeni kuşak teknoloji ile daha çok iç içedir. Alfa kuşağı, 2010 yılından sonra doğan gruba aittir. Bu nesil son kuşak olmasına rağmen, teknoloji kullanımı, araştırma etkinlikleri ve eleştirel vizyon özellikleri ile karakterize edilir. Eğitim süreçlerinde fiziksel temas iletişimde teknolojik araçların daha yaygın kullanımı sonucunda azalacaktır (dos Reis, 2018).

X kuşağından sonraki kuşaklar Prensky (2001) tarafından "dijital yerli" olarak adlandırılmıştır. Prensky (2001)'e göre teknolojik olarak zengin ortamda büyüyen dijital yerlilerin beyinlerinde, eski nesillere kıyasla temelde farklı şekillerde düşünmeleri ve işlemeleri anlamına gelen varsayımsal değişiklikler bulunmaktadır. Buna göre dijital yerliler bilgiyi çok hızlı almaya alışkındır, grafikleri metinlerden önce tercih eder, bilgisayar, dijital oyun ve İnternet dilini ana dil gibi konuşurlar. Dijital yerliler olan günümüz öğretmen adayları, her ne kadar önceki nesillere göre teknoloji içerisinde büyüseler de Lei (2009)'ye göre, temel teknolojiler ve sosyal iletişim teknolojileri konusunda bilgili olmalarına rağmen hem dar kapsam hem de teknoloji faaliyetlerindeki derinlik eksikliği nedeniyle teknoloji yeterlilikleri sınırlıdır.

TDK (2021) kaygıyı “Üzüntü, endişe duyulan düşünce, gam, tasa” ve “Genellikle kötü bir şey olacakmış düşüncesiyle ortaya çıkan ve sebebi bilinmeyen gerginlik duygusu" olarak tanımlanmaktadır. Millar ve Walsh (2000) kaygıyı, fiziksel belirtilerle kendisini gösteren, anormal ve nedensiz bir şekilde ortaya çıkan aşırı korku hali olarak tanımlamıştır. Genel anlamda kaygı türlerini inceleyen farklı çalışmalar bulunmaktadır. Bunlardan birisi Spielberger (1966) tarafından kaygının, durumluk ve sürekli kaygı şeklinde iki farklı tipinin tanımlanmasıdır (Köknel, 2014). Durumluk kaygı, belirli durumlarda yaşanır ve bu durumlar kaybolduğunda yok olur (Kuzucu, 2013). Sürekli kaygı, durumluk kaygıya kıyasla durağan ve süreklidir. Kişilik yapısındaki kaygıya yatkınlık sürekli kaygı düzeyini etkilemektedir (Köknel, 2014). Literatür incelendiğinde okul öncesi öğretmen adaylarının çeşitli kaygılarını inceleyen çalışmalar göze çarpmaktadır (Avcı, Karababa ve Zencir, 2019; Gümrükçü Bilgici ve Deniz, 2016a, 2016b).

Okul öncesi öğretmen adaylarının da yer aldığı çeşitli çalışma grupları ve örneklemler üzerinde öğretmen adaylarının eğitimde çeşitli teknolojilerin kullanımına yönelik tutumlarına yönelik çalışmalar göze çarpmaktadır. Şahin ve Namlı (2019), okul öncesi öğretmen adayları ile diğer bölümlerde öğrenim gören öğretmen adaylarının eğitimde teknoloji kullanmaya ilişkin tutumları arasında farklılık bulunmadığını saptamışlardır. Yavuz Mumcu ve Dönmez Usta (2014) okul öncesi öğretmen adaylarının bilgisayar ve İnterneti en çok araştırma/ödev ve ikinci olarak sosyal paylaşım (iletişim) için kullandıklarını ifade etmiştir. Ayrıca okul öncesi öğretmen adayları ile diğer bölümlerde öğrenim gören öğretmen adaylarının bilgisayar ve İnternet kullanmaya yönelik tutumları arasında fark bulunmadığını rapor etmişlerdir.

Okur Akçay ve Halmatov (2015), okul öncesi öğretmen adaylarının bilgisayar destekli eğitim yapma konusundaki tutumları arasında cinsiyet, sınıf düzeyi ve bilgisayar sahibi olma değişkenlerine göre farklılık 
olmadığını sadece bilgisayar kullanım sıklığı değişkenine göre bir fark bulunduğunu belirtmişlerdir. Buna göre daha sık bilgisayar kullanan okul öncesi öğretmen adaylarının bilgisayar destekli eğitim konusunda daha olumlu tutuma sahip olduğunu ifade etmişlerdir. Zelyurt ve Tuncer (2016)'da benzer şekilde daha sik bilgisayar kullanan okul öncesi öğretmen adaylarının bilgisayar destekli eğitime karşı daha olumlu tutum içerisinde olduklarını rapor etmişlerdir. Polat ve Karakuş (2020)'nin çalışmalarında, diğer bölümlerde öğrenim gören öğretmen adayları ile okul öncesi öğretmen adaylarının bilgisayar destekli eğitime yönelik tutumları arasında herhangi bir farklılık gözlenmemiştir.

Turgut ve Akdemir (2019), bölümlere göre öğretmen adaylarının mobil öğrenmeye karşı tutumlarını incelemişlerdir. Bu doğrultuda mobil öğrenme tutumlarına ait "avantaj", "sınırlılık", "kullanışlılık" ve "özgürlük" şeklinde dört alt boyut ortaya koymuşlarıdır. Okul öncesi öğretmen adaylarının mobil öğrenme konusunda olumlu tutum içerisinde olduğunu belirtmişlerdir. Sancar Tokmak, Yavuz Konokman ve Yanpar Yelken (2013), okul öncesi öğretmen adaylarının teknolojik pedagojik alan bilgisi özgüven algılarının yüksek olduğunu ifade etmişlerdir. Literatürdeki çalışmalar incelendiğinde genel anlamda okul öncesi öğretmen adaylarının eğitimde teknoloji kullanımına yönelik tutumlarının olumlu olduğu söylenebilir.

Okullar, bilgi ve iletişim teknolojileri ile tanıştığında, öğretmenler bunları sınıfta kullanmak, onları kullanmayı öğrenmek ve başarısızlıkları ile başa çıkmak konusunda oldukça endişelenmiştir (Rosen ve Weil 1995). Alan yazın, öğretmenlerin uzun zamandır sınıflarında kullanmaktan korktukları için bilgisayara karşı olumlu tutumlarının olmadığını (Hardy, 1998), teknolojiyi sınıf eğitimine entegre etmek için kendilerini iyi hissetmediklerini ve bilgisayarı kullanma konusunda düşük bir güven düzeyine sahip olduklarını bildirmektedir. Aslında öğretmenler, öğrencilerine teknolojik yeterlilik eksiklerini göstermekten endişe duyarken, giderek daha fazla talepte bulunmaya başlayan öğrenciler, öğretmenlerden bilgisayar kullanımı alanında uzman ve rol model olmaların beklemektedir (Revilla Munoz, Alpiste Penalba, Fernandez Sanchez ve Santos, 2017).

Teknolojinin kullanımı zaman alır ve öğretmenlerin bunu benimsemesi için bir paradigma değişikliği gerekir. Bu değişiklik için en kritik noktalar öğretmenlerin hazır olma durumu, nasıl davrandıkları ve teknoloji entegrasyonudur (Baturay, Gökçearslan ve Ke, 2017). Eğitimsel teknoloji dendiğinde kuşkusuz ilk akla gelen eğitimde bilgisayar kullanımıdır. Bilgisayar kaygısı, bilgisayarların işyerlerine girmesinden bu yana literatürde incelenen ve bilgisayarlar hakkında çok az şey bilen kullanıcıların kaygı duyma olasılığının daha yüksek olduğunu gösteren, yaygın olarak ortaya çıkan bir durumdur (Torkzadeh ve Angulo 1992). Beckers, Wicherts ve Schmidt (2007) bilgisayar kaygısının durum kaygısı ile mi yoksa sürekli kaygı ile mi ilişkili olduğunu incelemişler ve bilgisayar kaygısının, durumluk kaygıdan çok sürekli kaygı ile ilişkili olduğunu ifade etmişlerdir. Bilgisayar okuryazarı olmak, üniversite düzeyindeki tüm öğrencilerin akademik ilerlemesi için zorunlu hale gelmektedir ve öğrencilerin günlük olarak bu kritik beceriyi kullanarak akademik görevleri ve araştırmaları yürütmeleri gerekmektedir (Schlebusch, 2018).

Teknolojinin eğitim içerisindeki kullanımı değiştikçe öğretmenlerin rolü de değişmektedir. Öğrencilerin aktif öğrenenler olduğu öğrenci merkezli yaklaşımlar, teknoloji ile sosyalleşme, eğitimsel oyunlar, uzaktan öğretim/öğrenme, web toplulukları gibi olgular bu değişim sürecinin yansımaları olabilir (Yalçınalp ve Cabı, 2015). Diğer eğitim araçları gibi teknoloji de, erken çocukluk dönemi eğitimcilerinin, çocukların öğrenme hedeflerini desteklemek için gelişimsel olarak uygun uygulamalar çerçevesinde kullandığında faydalı olur ve çocuklar bilgiyi uygulamalı, ilgi çekici ve güçlendirici yollarla genişletmek için kullandıklarında teknoloji öğrenmeyi en iyi şekilde destekler (Shillady ve Parikh, 2012). Eğitim teknolojisi kullanımı ve teknolojinin eğitime entegrasyonu konusunda öğretmen adaylarının kaygı düzeyini belirleme çalışmalarında bu unsurların dikkate alınması bu açıdan önem arz etmektedir (Yalçınalp ve Cabı, 2015). Ayrıca öğretmenler, çocukların teknoloji kullanımı için dikkatlice düşünmeli ve sınırlar koymalıdır. Eğitimciler, çocuklar için kullanılacak teknolojiyi seçerken daha seçici olmalıdır (Shillady ve Parikh, 2012). The National Association for the Education of Young Children, 8 yaşına kadar çocukların eğitim programlarında teknoloji kullanımına yönelik olarak aşağıdaki bazı temel noktaları vurgulamışlardır (NAEYC, 2012);

- Teknoloji araçları ve interaktif medyanın kullanımı çocuklara zarar vermemelidir. 
- Gelişimsel olarak uygun uygulamalar, teknoloji ve etkileşimli medyanın erken çocukluk programlarına entegre edilip edilmeyeceğine ve ne zaman entegre edileceğine dair kararlara rehberlik edilmelidir.

- Gelişimsel olarak uygun öğretim uygulamaları, teknoloji ve etkileşimli medya dahil olmak üzere herhangi bir sınıf materyalinin seçimine daima rehberlik edilmelidir.

- Teknoloji ve medyanın uygun kullanımı, her çocuğun yaşına, gelişim düzeyine, ihtiyaçlarına, ilgi alanlarına, dil geçmişine ve yeteneklerine bağlıdır.

- Teknoloji ve medyanın etkin kullanımları aktif, uygulamalı, ilgi çekici ve güçlendiricidir. Görevlerin yerine getirilmesini kolaylaştırmak için uyarlanabilir yöntemler sağlamak ve çocukların öğrenmesini desteklemek için birçok seçenekten biri olarak kullanılır.

- Uygun şekilde kullanıldığında teknoloji ve medya çocukların bilişsel ve sosyal yeteneklerini geliştirebilir.

- Teknoloji ve medya, çevreye, müfredata ve günlük rutinlere entegre edildiğinde erken çocukluk pratiğini geliştirebilir.

\section{Araştırmanın Amacı}

Okul öncesi öğretmen adaylarının eğitimde teknoloji kullanımı kaygılarının incelenmesi ve hangi değişkenlerin bu kaygı üzerinde etkili olduğunu belirlemek bu çalışmanın genel amacıdır. Bu doğrultuda aşağıdaki araştırma problemlerine yanıt aranacaktır:

P1) Eğitimde teknoloji kullanımına yönelik kaygılar, okul öncesi öğretmen adaylarının cinsiyetlerine göre değişmekte midir?

P2) Eğitimde teknoloji kullanımına yönelik kaygılar, okul öncesi öğretmen adaylarının öğrenim gördükleri üniversite türüne (devlet/vakıf) göre değişmekte midir?

P3) Eğitimde teknoloji kullanımına yönelik kaygılar, okul öncesi öğretmen adaylarının öğrenim gördükleri sinıf düzeyine göre değişmekte midir?

P4) Eğitimde teknoloji kullanımına yönelik kaygılar, okul öncesi öğretmen adaylarının bilgisayar sahiplik durumlarına göre değişmekte midir?

P5) Okul öncesi öğretmen adaylarının, eğitimde teknoloji kullanımına yönelik kaygıları ile yaşları arasında ilişki var mıdır?

\section{Araştırmanın Varsayımları}

Araştırmada eğitim fakültesinden mezun olan veya formasyon eğitimi alan, aktif olarak öğretmenlik mesleğini yapmaya başlamamış okul öncesi öğretmenlerinin okul öncesi öğretmen adayı olduğu varsayılmıştır. Okul öncesi öğretmen adayları tarafından kişisel bilgisayar sahibi olma/olmama durumunun dizüstü ve masaüstü bilgisayarlar düşünülerek cevaplandığı varsayılmıştır.

\section{Yöntem}

Okul öncesi öğretmen adaylarının eğitimde teknoloji kullanımı kaygılarının incelenmesini amaçlayan bu araştırma ilişkisel tarama modelindedir. İlişkisel tarama modelinin kullanıldığı araştırmalarda, iki veya daha fazla değişken arasında bulunan değişimin varlığını veya derecesini belirlemek amaçlanır (Karasar, 2015).

\section{Çalışma Grubu}

Araştırmanın çalışma grubu küme tipi rastgele örnekleme ile belirlenmiştir. Bu örnekleme yöntemi, evren genişliğinin büyük ve geniş bir coğrafyaya ait olduğu durumlarda evren kümelere ayrılarak kullanılır (Kılıç, 2012). Bu doğrultuda çalışma grubunu, çeşitli üniversitelerin eğitim fakültelerinin okul öncesi öğretmenliği bölümlerinde öğrenim gören 203 okul öncesi öğretmen adayı ve bu bölümlerden mezun olup herhangi bir öğretmenlik deneyimi olmayan 346 okul öncesi öğretmeni oluşturmuştur. Dolayısıyla çalışma grubunu toplam 549 okul öncesi öğretmen adayı oluşturmuştur. Çalışma grubunun yaş ortalaması 24,81 'dir ve çeşitli demografik özellikleri Tablo 1'de 
verilmiştir.

Tablo 1. Çalışma grubunun demografik özellikleri

\begin{tabular}{llcc}
\hline \multicolumn{1}{c}{ Değişken } & & $f$ & Yüzde (\%) \\
\hline \multirow{2}{*}{ Cinsiyet } & Kadın & 510 & 92,9 \\
& Erkek & 39 & 7,1 \\
\hline \multirow{2}{*}{ Üniversite } & Devlet & 513 & 93,4 \\
& Vakıf & 36 & 6,6 \\
\hline \multirow{2}{*}{ Eğitim Fakültesi mezunu } & Evet & 541 & 98,5 \\
& Hayır & 8 & 1,5 \\
\hline \multirow{4}{*}{ Sınıf } & Birinci Sınıf & 40 & 7,3 \\
& İkinci Sınıf & 46 & 8,4 \\
& Üçüncü Sınıf & 39 & 7,1 \\
& Dördüncü Sınıf veya üzeri & 78 & 14,2 \\
\multirow{2}{*}{ Kişisel bilgisayar sahibi } & Mezun & 346 & 63,0 \\
\hline
\end{tabular}

Çalışmaya katılan okul öncesi öğretmen adaylarının \%92,9'u kadındır. Adayların 513'ü 56 farklı devlet üniversitesi (\%93,4), 36'sı 11 farklı vakıf üniversitesi $(\% 6,6)$ öğrencisi veya mezunudur. Çalışma grubundaki okul öncesi öğretmen adaylarının sadece \%1,5'i eğitim fakültesi mezunu olmayıp pedagojik formasyon sertifikası sahibidir. Okul öncesi öğretmen adaylarının \%63'ü mezun durumdadır ve \%79,8'i kişisel bilgisayar sahibidir.

\section{Veri Toplama Araçları}

Araştırmanın verileri, okul öncesi öğretmen adaylarının cinsiyetleri, yaşları, öğrenim gördükleri üniversite, sınıfları ve kişisel bilgisayar sahibi olup olmadıklarının sorulduğu "Demografik Bilgi Formu" ve Yalçınalp ve Cabı (2015) tarafından geliştirilen "Eğitim Teknolojileri Kullanımı Kaygı Ölçeği" kullanılarak toplanmıştır. Eğitim Teknolojileri Kullanımı Kaygı Ölçeği, bir vakıf üniversitesinde öğrenim görmekte olan 215 öğretmen adayının katılımıyla geliştirilmiştir. Toplam 5 alt boyut ve 24 maddeden oluşan ölçek 5'li Likert tipindedir. Ölçekte "Kesinlikle Kaygılanmıyorum" (1 puan), "Kaygılanmıyorum" (2 puan), "Kararsızım" (3 puan), "Kaygılanıyorum" (4 puan) ve "Kesinlikle Kaygılanıyorum" (5 puan) şeklinde puanlanmıştır. Beş alt boyut sırasıyla; "Görev Yeri Merkezli Kaygı (GYMK)" (4 madde), "Teknoloji Dezavantaj-Kısıtlılık Merkezli Kayg1 (TDKMK)" (7 madde), “Teknoloji-Entegrasyonu Merkezli Kaygı (TEMK)" (5 madde), “Teknoloji Yönetimi Merkezli Kaygı (TYMK)" (5 madde) ve "Teknik Merkezli Kaygı (TMK)" (3 madde) şeklindedir. Ölçeğin ters puanlanan herhangi bir maddesi yoktur ve puan arttıkça kaygı düzeyi de artmaktadır.

GYMK, öğretmen adayının görev yapacağı okuldaki teknolojik altyapı ve okul yönetiminin eğitimde teknoloji kullanımına bakış açısına yönelik kaygıları içermektedir. TDKMK, öğretmen adayının öğrencilerin yeterince teknoloji okur-yazarı olmama durumları, teknolojiyi kötü kullanma ve kurumun maddi imkânsızlık nedeniyle yeterince teknolojiyi destekleyememesi konusundaki kaygıları kapsamaktadır. TEMK, öğretmen adayının kendisinin gelişen teknolojiye ayak uyduramaması hakkındaki kaygıları iken TYMK, kullanacağı teknolojilerin kendisine veya öğrencilerine uygun olmaması ve diğer meslektaşları ile ilgili kaygılardır. TMK ise yine öğretmen adayının kendisi ile ilgili kaygılarından birisi olup adayın donanım/teknik bilgisinin yetersiz kalma durumları ile alakalıdır.

\section{Verilerin Toplanması}

Araştırma verileri, gerekli etik kurul izinleri alındıktan sonra devam eden Covid-19 salgını sebebi ile yüz yüze toplanamamış, gönüllülük esasına dayalı olarak okul öncesi öğretmen adaylarından elektronik ortamda toplanmıştır. Eğitim Teknolojileri Kullanımı Kaygı Ölçeği, alt boyutlarının iç tutarlılık katsayısı Cronbach alfa değerleri sırasıyla, GYMK için 0,871; TDKMK için 0,711; TEMK için 0,887; TYMK için 0,723; TMK için 0,727 olarak hesaplanmıştır. Güvenirlik analizi sonuçlarına göre ölçme aracının, eğitim teknolojileri kullanımı kaygılarını ölçmek için uygun olduğu (>70) söylenebilir (Büyüköztürk, 2003). 


\section{Bulgular ve Yorum}

$\mathrm{Bu}$ bölümde, araştırma verilerine göre okul öncesi öğretmen adaylarının eğitimde teknoloji kullanımı kaygıları cinsiyet, üniversite türü, öğrenim gördükleri sınıf, bilgisayar sahiplik durumu ve yaş değişkenlerine göre incelenecektir.

Tablo 2. Okul öncesi öğretmen adaylarının eğitimde teknoloji kullanımı kaygılarının betimsel istatistikleri

\begin{tabular}{lccc}
\hline Alt Boyut & $f$ & $\bar{X}$ & $S S$. \\
\hline GYMK & 549 & 2,14 & 0,84 \\
TDKMK & 549 & 2,24 & 0,64 \\
TEMK & 549 & 2,94 & 1,06 \\
TYMK & 549 & 2,81 & 0,83 \\
TMK & 549 & 3,33 & 0,91 \\
Toplam Kaygi Puanı & 549 & 2,69 & 0,65 \\
\hline
\end{tabular}

Tablo 2 incelendiğinde, okul öncesi öğretmen adaylarının eğitim teknolojileri kullanımı kaygı ölçeği alt boyutları arasında en yüksek ortalamaya sahip alt boyutun TMK $(\bar{X}=3,33 ; S S=0,65)$, en düşük ortalamaya sahip alt boyutun ise GYMK $(\bar{X}=2,14 ; S S=0,84)$ olduğu saptanmıştır.

Tablo 3 Okul öncesi öğretmen adaylarının eğitimde teknoloji kullanımı kaygı ölçeği puanlarının normal dă̆ılım testi sonuçları

\begin{tabular}{lcc}
\hline Alt Boyut & Çarpıklık & Basıklık \\
\hline GYMK & 0,840 & 0,498 \\
TDKMK & 0,450 & 0,058 \\
TEMK & $-0,730$ & $-0,970$ \\
TYMK & 0,134 & $-0,364$ \\
TMK & $-0,371$ & $-0,352$ \\
Toplam Kayg1 Puan1 & 0,079 & $-0,305$ \\
\hline$* *$ * $<0,01$ & &
\end{tabular}

Tablo 3'te görüldüğü üzere okul öncesi öğretmen adaylarının eğitimde teknoloji kullanımı kaygı ölçeği puanlarının çarpıklık ve basıklık değerlerinin -1 ile 1 arasında kaldığı saptanmıştır. Buna göre dağılımın normale yakın olduğu kabul edilebilir (Köklü, Büyüköztürk, Çokluk-Bökeoğlu, 2007).

Tablo 4. Okul öncesi öğretmen adaylarının eğitim teknolojileri kullanımı kaygı ölçeği alt boyutları puanlarının cinsiyetlerine göre bağımsız örneklemler t-testi sonuçları

\begin{tabular}{|c|c|c|c|c|c|c|c|}
\hline Alt Boyut & Cinsiyet & $f$ & $\overline{\mathrm{X}}$ & SS. & S.d. & $t$ & $p$ \\
\hline \multirow{2}{*}{ GYMK } & Kadın & 510 & 2,14 & 0,84 & \multirow{2}{*}{43,941} & \multirow{2}{*}{$-0,530$} & \multirow{2}{*}{0,599} \\
\hline & Erkek & 39 & 2,21 & 0,84 & & & \\
\hline \multirow{2}{*}{ TDKMK } & Kadın & 510 & 2,24 & 0,64 & \multirow{2}{*}{46,210} & \multirow{2}{*}{0,061} & \multirow{2}{*}{0,951} \\
\hline & Erkek & 39 & 2,23 & 0,55 & & & \\
\hline \multirow{2}{*}{ TEMK } & Kadın & 510 & 2,93 & 1,06 & \multirow{2}{*}{44,940} & \multirow{2}{*}{$-0,587$} & \multirow{2}{*}{0,560} \\
\hline & Erkek & 39 & 3,03 & 0,99 & & & \\
\hline \multirow{2}{*}{ TYMK } & Kadın & 510 & 2,80 & 0,82 & \multirow{2}{*}{42,893} & \multirow{2}{*}{$-1,057$} & \multirow{2}{*}{0,296} \\
\hline & Erkek & 39 & 2,96 & 0,91 & & & \\
\hline \multirow{2}{*}{ TMK } & Kadın & 510 & 3,31 & 0,92 & \multirow{2}{*}{44,853} & \multirow{2}{*}{$-1,449$} & \multirow{2}{*}{0,154} \\
\hline & Erkek & 39 & 3,52 & 0,86 & & & \\
\hline Toplam Kayg1 & Kadın & 510 & 2,68 & 0,66 & \multirow{2}{*}{44,386} & \multirow{2}{*}{$-1,006$} & \multirow{2}{*}{0,320} \\
\hline Puanı & Erkek & 39 & 2,79 & 0,64 & & & \\
\hline
\end{tabular}

Tablo 4 incelendiğinde, cinsiyetlerine göre okul öncesi öğretmen adaylarının eğitim teknolojileri kullanımı kayg1 ölçeğinin GYMK $\left(t_{(43,941)}=-0,530 ; p>0,05\right)$, TDKMK $\left(t_{(46,210)}=0,061 ; p>0,05\right)$, TEMK $\left(t_{(44,940)}=\right.$ $-0,587 ; p>0,05)$, TYMK $\left(t_{(42,893)}=-1,057 ; p>0,05\right)$, TMK $\left(t_{(44,853)}=-1,449 ; p>0,05\right)$ alt boyutu puanları ve toplam kaygı puanları $\left(t_{(44,386)}=-1,006 ; p>0,05\right)$ arasında istatistiksel olarak anlamlı fark saptanmamıştır.

Tablo 5. Okul öncesi öğretmen adaylarının eğitim teknolojileri kullanımı kaygı ölçeği alt boyutları puanlarının üniversite türüne göre bağımsız örneklemler t-testi sonuçları

\begin{tabular}{cccccccc}
\hline Alt Boyut & Cinsiyet & $f$ & $\bar{X}$ & SS. & S.d. & $t$ & $p$ \\
\hline \multirow{2}{*}{ GYMK } & Devlet & 513 & 2,15 & 0,84 & \multirow{2}{*}{40,162} & \multirow{2}{*}{0,389} & 0,699 \\
& Vakıf & 36 & 2,09 & 0,83 & & & \\
& & &
\end{tabular}


Okul Öncesi Öğretmen Adaylarının Eğitimde Teknoloji Kullanımına Yönelik...

\begin{tabular}{|c|c|c|c|c|c|c|c|}
\hline \multirow{2}{*}{ TDKMK } & Devlet & 513 & 2,24 & 0,63 & \multirow{2}{*}{39,926} & \multirow{2}{*}{0,443} & \multirow{2}{*}{0,660} \\
\hline & Vakıf & 36 & 2,19 & 0,64 & & & \\
\hline \multirow{2}{*}{ TEMK } & Devlet & 513 & 2,93 & 1,06 & \multirow{2}{*}{39,495} & \multirow{2}{*}{$-0,456$} & \multirow{2}{*}{0,651} \\
\hline & Vakıf & 36 & 3,02 & 1,12 & & & \\
\hline \multirow{2}{*}{ TYMK } & Devlet & 513 & 2,81 & 0,83 & \multirow{2}{*}{39,859} & \multirow{2}{*}{0,249} & \multirow{2}{*}{0,805} \\
\hline & Vakıf & 36 & 2,78 & 0,85 & & & \\
\hline \multirow{2}{*}{ TMK } & Devlet & 513 & 2,69 & 0,65 & \multirow{2}{*}{40,911} & \multirow{2}{*}{0,631} & \multirow{2}{*}{0,532} \\
\hline & Vakıf & 36 & 2,66 & 0,66 & & & \\
\hline \multirow{2}{*}{ Toplam Kaygı Puanı } & Devlet & 513 & 2,69 & 0,65 & \multirow{2}{*}{39,913} & \multirow{2}{*}{0,259} & \multirow{2}{*}{0,799} \\
\hline & Vakıf & 36 & 2,66 & 0,66 & & & \\
\hline
\end{tabular}

Tablo 5 incelendiğinde, devlet ve vakıf üniversitelerinde öğrenim gören okul öncesi öğretmen adaylarının eğitim teknolojileri kullanımı kaygı ölçeğinin GYMK $\left(t_{(40,162)}=0,389 ; p>0,05\right)$, TDKMK $\left(t_{(39,926)}=\right.$ $0,443 ; p>0,05)$, TEMK $\left(t_{(39,495)}=-0,456 ; p>0,05\right)$, TYMK $\left(t_{(39,859)}=0,249 ; p>0,05\right)$, TMK $\left(t_{(40,911)}=\right.$ $0,631 ; p>0,05)$ alt boyutları puanları ve toplam kayg1 puanları $\left(t_{(39,913)}=0,259 ; p>0,05\right)$ arasinda istatistiksel olarak anlamlı fark bulunmadığı belirlenmiştir.

Tablo 6. Okul öncesi öğretmen adaylarının eğitim teknolojileri kullanımı kaygı ölçeği alt boyutları puanlarının sımıf değişkenine göre ortalama ve standart sapma değerleri

\begin{tabular}{|c|c|c|c|c|c|c|c|c|c|c|c|}
\hline Alt Boyut & Grup & $f$ & $\bar{X}$ & SS. & Var. Kay. & $K T$ & $S d$ & $K O$ & $F$ & $p$ & Fark \\
\hline \multirow{5}{*}{ GYMK } & I. 1. Sinif & 40 & 2,34 & 0,98 & G. Arasi & 2,905 & 4 & 0,726 & 1,033 & 0,390 & \\
\hline & II. 2. Sinif & 46 & 2,04 & 0,59 & G. içi & 382,629 & 544 & 0,703 & & & \\
\hline & III. 3. Sinif & 39 & 2,20 & 0,96 & Toplam & 385,534 & 548 & & & & \\
\hline & IV. 4. Sınıf ve üzeri & 78 & 2,21 & 0,79 & & & & & & & \\
\hline & V. Mezun & 346 & 2,11 & 0,84 & & & & & & & \\
\hline \multirow{5}{*}{ TDKMK } & I. 1. Sinif & 40 & 2,22 & 0,70 & G. Aras1 & 1,622 & 4 & 0,406 & 1,025 & 0,394 & \\
\hline & II. 2. Sinif & 46 & 2,06 & 0,41 & G. içi & 215,287 & 544 & 0,396 & & & \\
\hline & III. 3. Sinif & 39 & 2,29 & 0,59 & Toplam & 216,909 & 548 & & & & \\
\hline & IV. 4. Sınıf ve üzeri & 78 & 2,25 & 0,58 & & & & & & & \\
\hline & V. Mezun & 346 & 2,25 & 0,66 & & & & & & & \\
\hline \multirow{5}{*}{ TEMK } & I. 1. Sinif & 40 & 2,81 & 1,07 & G. Arasi & 5,708 & 4 & 1,427 & 1,275 & 0,278 & \\
\hline & II. 2. Sinif & 46 & 2,65 & 0,99 & G. içi & 608,573 & 544 & 1,119 & & & \\
\hline & III. 3. Sinif & 39 & 2,97 & 0,97 & Toplam & 614,280 & 548 & & & & \\
\hline & IV. 4. Sınıf ve üzeri & 78 & 2,91 & 1,03 & & & & & & & \\
\hline & V. Mezun & 346 & 3,00 & 1,08 & & & & & & & \\
\hline \multirow{5}{*}{ TYMK } & I. 1. Sinif & 40 & 2,59 & 0,78 & G. Arasi & 6,774 & 4 & 1,694 & 2,493 & $0,042^{*}$ & $\mathrm{I}-\mathrm{V}^{*}$ \\
\hline & II. 2. Sinif & 46 & 2,58 & 0,69 & G. içi & 369,471 & 544 & 0,679 & & & II- $-V^{*}$ \\
\hline & III. 3. Sinif & 39 & 2,74 & 0,85 & Toplam & 376,245 & 548 & & & & \\
\hline & IV. 4. Sınıf ve üzeri & 78 & 2,76 & 0,77 & & & & & & & \\
\hline & V. Mezun & 346 & 2,89 & 0,85 & & & & & & & \\
\hline \multirow{5}{*}{ TMK } & I. 1. Sinif & 40 & 2,97 & 0,89 & G. Aras1 & 17,066 & 4 & 4,267 & 5,265 & $0,000^{* *}$ & I-IV* \\
\hline & II. 2. Sinıf & 46 & 2,91 & 0,99 & G. içi & 440,806 & 544 & 0,810 & & & $\mathrm{I}-\mathrm{V}^{* *}$ \\
\hline & III. 3. Sinif & 39 & 3,33 & 0,82 & Toplam & 457,872 & 548 & & & & II-III ${ }^{*}$ \\
\hline & IV. 4. Sınıf ve üzeri & 78 & 3,51 & 0,81 & & & & & & & II-IV $* *$ \\
\hline & V. Mezun & 346 & 3,38 & 0,92 & & & & & & & $\mathrm{II}-\mathrm{V}^{* *}$ \\
\hline \multirow{5}{*}{$\begin{array}{l}\text { Toplam } \\
\text { Kayg1 Puanı }\end{array}$} & I. 1. Sinif & 40 & 2,59 & 0,69 & G. Arası & 3,707 & 4 & 0,927 & 2,187 & 0,069 & \\
\hline & II. 2. Sinıf & 46 & 2,45 & 0,51 & G. içi & 230,500 & 544 & 0,424 & & & \\
\hline & III. 3. Sinif & 39 & 2,71 & 0,67 & Toplam & 234,208 & 548 & & & & \\
\hline & IV. 4. Sınıf ve üzeri & 78 & 2,73 & 0,60 & & & & & & & \\
\hline & V. Mezun & 346 & 2,73 & 0,67 & & & & & & & \\
\hline
\end{tabular}

Tablo 6'ya göre, okul öncesi öğretmen adaylarının öğrenim gördüğü sınıfa göre eğitim teknolojileri kullanımı kaygı ölçeğinin alt boyutları olan GYMK $(F=1,033 ; p>0,05)$, TDKMK $(F=1,025 ; p>0,05)$, TEMK $(F=1,275 ; p>0,05)$ puanları ve toplam kaygı puanları $(F=2,187 ; p>0,05)$ arasında istatistiksel olarak anlamlı bir ilişki bulunmamaktadır. Okul öncesi öğretmen adaylarının öğrenim görmekte oldukları sınıfa göre, TYMK puanları arasında anlamlı bir ilişki olduğu görülmektedir $(F=2,493 ; p<0,05)$. Bu ilişkinin kaynağını araştırmak için varyansların eşit olması sebebiyle Post Hoc testlerinden LSD testi uygulanmıştır. Test sonucuna göre mezun okul öncesi öğretmen adaylarının TYMK puanları ile birinci ve 
ikinci sınıfta öğrenim gören okul öncesi öğretmen adaylarının puan ortalaması arasındaki fark istatistiksel olarak anlamlıdır $(p<0,05)$. Yine okul öncesi öğretmen adaylarının öğrenim görmekte oldukları sınıfa göre TMK puanları arasında anlamlı bir ilişki bulunmaktadır $(F=5,265 ; p<0,01)$. LSD testine göre birinci sınıfta öğrenim gören okul öncesi öğretmen adayların puanları, dördüncü sinıf ve üzerindeki öğretmen adayları $(p<0,05)$ ile mezun adayların $(p<0,01)$ puan ortalamaları arasındaki farklar, ikinci sınıfta bulunan adaylar ile üçüncü sınıf $(p<0,05)$, dördüncü sınıf ve üzeri $(p<0,01)$, mezun adayların $(p<0,01)$ puan ortalamaları arasındaki farklar istatistiksel olarak anlamlıdır.

Tablo 7. Okul öncesi öğretmen adaylarının eğitim teknolojileri kullanımı kaygı ölçeği alt boyutları puanlarının kişisel bilgisayar sahibi olma durumuna göre bağımsız örneklemler t-testi sonuçları

\begin{tabular}{|c|c|c|c|c|c|c|c|}
\hline Alt Boyut & Bilgisayar sahibi & $f$ & $\bar{X}$ & SS. & S.d. & $t$ & $p$ \\
\hline \multirow{2}{*}{ GYMK } & Evet & 438 & 2,14 & 0,84 & \multirow{2}{*}{170,719} & \multirow{2}{*}{$-0,150$} & \multirow{2}{*}{0,881} \\
\hline & Hayır & 111 & 2,15 & 0,84 & & & \\
\hline \multirow{2}{*}{ TDKMK } & Evet & 438 & 2,25 & 0,64 & \multirow{2}{*}{177,866} & \multirow{2}{*}{1,384} & \multirow{2}{*}{0,168} \\
\hline & Hayır & 111 & 2,16 & 0,60 & & & \\
\hline \multirow{2}{*}{ TEMK } & Evet & 438 & 2,96 & 1,05 & \multirow{2}{*}{166,389} & \multirow{2}{*}{0,983} & \multirow{2}{*}{0,327} \\
\hline & Hayır & 111 & 2,85 & 1,08 & & & \\
\hline \multirow{2}{*}{ TYMK } & Evet & 438 & 2,86 & 0,82 & \multirow{2}{*}{167,742} & \multirow{2}{*}{2,458} & \multirow{2}{*}{$0,015^{*}$} \\
\hline & Hayır & 111 & 2,64 & 0,84 & & & \\
\hline \multirow{2}{*}{ TMK } & Evet & 438 & 3,39 & 0,88 & \multirow{2}{*}{157,757} & \multirow{2}{*}{3,122} & \multirow{2}{*}{$0,002^{* *}$} \\
\hline & Hayır & 111 & 2,58 & 0,99 & & & \\
\hline Toplam Kayg1 & Evet & 438 & 2,72 & 0,64 & \multirow{2}{*}{157,755} & \multirow{2}{*}{1,968} & \multirow{2}{*}{0,051} \\
\hline Puanı & Hayır & 111 & 2,58 & 0,71 & & & \\
\hline
\end{tabular}

Tablo 7 incelendiğinde, kişisel bilgisayar sahibi okul öncesi öğretmen adayları ile kişisel bilgisayar sahibi olmayanların eğitim teknolojileri kullanımı kaygı ölçeğinin GYMK $\left(t_{(170,719)}=-0,150 ; p>0,05\right)$, TDKMK $\left(t_{(177,866)}=1,384 ; p>0,05\right)$, TEMK $\left(t_{(166,389)}=0,983 ; p>0,05\right)$ puanlar1 ve toplam kayg1 $\left(t_{(157,755)}=\right.$ $1,968 ; p>0,05)$ puanları arasında istatistiksel olarak fark bulunmadığı belirlenmiştir. Diğer taraftan, kişisel bilgisayar sahibi okul öncesi öğretmen adaylarının TYMK $\left(t_{(167,742)}=2,458 ; p<0,05\right)$ ve TMK $\left(t_{(157,757)}=\right.$ 3,122; $p<0,01)$ kaygı puanları arasında istatistiksel olarak anlamlı fark saptanmıştır. Buna göre, kişisel bilgisayar sahibi okul öncesi öğretmen adaylarının, kişisel bilgisayar sahibi olmayan okul öncesi öğretmen adaylarına göre TYMK ve TMK puanları daha yüksektir.

Tablo 8. Okul öncesi öğretmen adaylarının eğitim teknolojileri kullanımı kaygı ölçeği alt boyutları puanları ile yaşları arasında Spearman korelasyon testi sonuçları

\begin{tabular}{|c|c|c|}
\hline Alt Boyut & İstatistik & \\
\hline \multirow{2}{*}{ GYMK } & Korelasyon katsayısı & $-0,017$ \\
\hline & $\mathrm{p}$ & 0,683 \\
\hline \multirow{2}{*}{ TDKMK } & Korelasyon katsayısı $(\rho)$ & 0,036 \\
\hline & $\mathrm{p}$ & 0,399 \\
\hline \multirow{2}{*}{ TEMK } & Korelasyon katsayısı $(\rho)$ & 0,094 \\
\hline & $\mathrm{p}$ & $0,028^{*}$ \\
\hline \multirow{2}{*}{ TYMK } & Korelasyon katsayısı $(\rho)$ & 0,110 \\
\hline & $\mathrm{p}$ & $0,01^{*}$ \\
\hline \multirow{2}{*}{ TMK } & Korelasyon katsayısı $(\rho)$ & 0,104 \\
\hline & $\mathrm{p}$ & $0,015^{*}$ \\
\hline
\end{tabular}

${ }^{* \mathrm{p}}<0,05$

Tablo 8'e göre, okul öncesi öğretmen adaylarının yaşları ile eğitim teknolojileri kullanımı kaygı ölçeği alt boyutlarından GYMK ve TDKMK puanları arasında anlamlı bir korelasyon bulunmamaktadır $(p>0,05)$. Öte yandan, okul öncesi öğretmen adaylarının yaşları ile eğitim teknolojileri kullanımı kaygı ölçeği alt boyutlarmdan TEMK $(\rho=0,094 ; p<0,05)$, TYMK $(\rho=0,110 ; p<0,05)$ ve TMK $(\rho=0,104 ; p<0,05)$ puanları arasında pozitif yönlü zayıf bir korelasyon saptanmıştır. Buna göre, okul öncesi öğretmen adaylarının yaşları arttıkça TEMK, TYMK ve TMK puanları da artmaktadır. 


\section{Sonuç ve Tartışma}

Okul öncesi öğretmen adaylarının, eğitimsel teknoloji kullanımına yönelik kaygılarının çeşitli değişkenlere göre incelenmesinin amaçlandığı bu çalışmada, okul öncesi öğretmen adaylarını en çok kaygılandıran alt boyutun "teknik merkezli kaygı", en az kaygılandıran alt boyutun ise "görev yeri merkezli kaygı" olduğu belirlenmiştir. Ömrüuzun (2019), sınıf içerisinde karmaşık cihazlar kullanan üst kademe öğretmenlerinin aksine okul öncesi öğretmenlerinin daha basit teknolojik cihazlar kullandıklarını ve kendisini öz yeterli hissetmeyen bir öğretmenin bile bazı temel cihazlar vasitasıla etkinliklerini kolayca yapabileceklerini ifade etmiştir. Bu doğrultuda, okul öncesi öğretmen adayları tarafından, 36-72 aylık çocuklara yönelik bir etkinlikte eğitimde teknoloji kullanımı konusunda yetkin görünmemek ve teknoloji konusunda çocukların daha yüksek beceriye sahip olduğunun düşünülmesi gibi durumlar en yüksek kaygının teknik merkezli kaygı alt boyutunda hissedilmesine sebep olmuş olabilir. Diğer taraftan okul öncesi öğretmenleri, okul yöneticilerinin okul öncesi eğitimde teknoloji kullanımına olumsuz bir bakış açısına sahip olduklarını düşünmektedir (Uçar-Kaplan, 2015). Bu çalışmanın evren ve örneklemini göreve başlamamış okul öncesi öğretmen adayları oluşturduğu için okulun teknolojik alt yapısı, okuldaki teknolojik araç-gereçlerin varlı̆̆ı ve okul yönetiminin teknoloji kullanımına bakış açısı okul öncesi öğretmen adaylarında kaygı yaratmamıştır şeklinde yorumlanabilir.

Sancar Tokmak ve diğerleri (2013), okul öncesi öğretmen adaylarının teknolojik pedagojik alan bilgisi özgüven algıları, Okur Akçay ve Halmatov (2015), bilgisayar destekli eğitim yapmaya yönelik tutumları, Zelyurt ve Tuncer (2016), bilgisayar destekli eğitime yönelik tutumları arasında cinsiyete göre farklılık bulunmadığını belirtmiştir. Bu araştırmada da teknolojiye yönelik tutum çalışmalarının bu sonuçlarına benzer olarak, okul öncesi öğretmen adaylarının eğitimde teknoloji kullanımına yönelik kaygılarının cinsiyetlerine göre farklılık göstermediği belirlenmiştir.

Yaşar Ekici, Türk, Asyalı ve Kıroğlu (2018), devlet ve vakıf üniversitesinde öğrenim gören okul öncesi öğretmen adaylarının teknoloji kabul ve kullanımının beş alt boyutu arasında fark olmadığını iki alt boyutu arasında fark olduğunu ifade etmiştir. Bu çalışmada, devlet ve vakıf üniversitelerinden mezun okul öncesi öğretmen adaylarının, eğitim teknolojileri kullanımına yönelik kaygıları arasında fark olmadığı saptanmıştır. Bu duruma eğitim fakültesinde öğrenim gören tüm okul öncesi öğretmen adaylarının temelde aynı derslerle desteklenmesi sebep olmuş olabilir.

Okul öncesi öğretmen adayının öğrenim görmekte olduğu sınıf düzeyinin; "görev yeri merkezli", "teknoloji dezavantaj/kısıtlılık merkezli" ve "teknoloji-entegrasyonu merkezli" kaygıları üzerinde bir etkisinin bulunmadığı belirlenmiştir. Diğer taraftan mezun okul öncesi öğretmen adaylarının, "teknoloji yönetimi merkezli" kaygılarının birinci ve ikinci sınıf adaylara göre daha yüksek olduğu; dördüncü sınıf veya mezun okul öncesi öğretmen adaylarının "teknik merkezli" kaygılarının birinci ve ikinci sınıf adaylara göre daha fazla olduğu saptanmıştır. Bu durumun okul öncesi öğretmen adayının yaşı ile ilgili olduğu düşünülebilir. Çünkü, araştırma bulgularında öğretmen adayının yaşı ilerlediğinde teknoloji yönetimi merkezli, teknoloji-entegrasyonu merkezli kaygılarının da arttığ 1 tespit edilmiştir. Ayrıca, mezun veya üst sınıflarda öğrenim görmekte olan okul öncesi öğretmen adaylarının öğretmenlik uygulaması derslerini almaları ve dolayısıyla mesleğe başladıklarında karşılaşacakları bazı problemleri fark etmiş olmaları kaygı düzeylerinde artışa sebep olmuş olabilir. Literatürde okul öncesi öğretmen adaylarının teknolojik pedagojik alan bilgisi özgüven algıları ve bilgisayar destekli eğitim yapmaya yönelik tutumlarının sınıf düzeyine göre değişmediğini rapor eden çalışmalar görülmektedir (Okur Akçay ve Halmatov, 2015; Sancar Tokmak ve diğerleri, 2013; Zelyurt ve Tuncer, 2016). Diğer taraftan üst sinıflarda öğrenim gören okul öncesi öğretmen adaylarının alt sınıflardaki öğretmen adaylarına göre daha pozitif yönde eğitimde teknoloji kullanımı tutumuna sahip olduğunu ifade eden çalışmalar da göze çarpmaktadır (Şahin ve Arslan Naml1, 2018).

Kişisel bilgisayar sahibi olmak okul öncesi öğretmen adaylarının, "görev yeri merkezli", "teknoloji dezavantaj-kısıtlılı merkezli" ve "teknoloji-entegrasyonu merkezli" kaygıları üzerinde bir fark yaratmamaktadır. Bu sonuçtan yola çıarak "görev yeri merkezli" ve "teknoloji dezavantaj-kısıtlılık merkezli" kaygıların kişisel bilgisayar sahibi olmak ile doğrudan bir ilişkisinin bulunmadığı söylenebilir. Diğer taraftan 
kişisel bilgisayarı olan okul öncesi öğretmen adayları, kişisel bilgisayarı olmayan okul öncesi öğretmen adaylarına göre daha yüksek "teknoloji yönetimi merkezli" ve "teknik merkezli" kaygı taşımaktadır. Bu durumun kişisel bilgisayar sahibi olan okul öncesi öğretmen adaylarının, yeterlik/yetersizliklerinin farkına varması ile ilgili olduğu düşünülmektedir. Kişisel bilgisayar sahibi olmayan okul öncesi öğretmen adayları gerekli uygulamaları kullanamadığı için yeterlik/yetersizliklerinin farkına varmamış olabilir.

\section{Öneriler}

Okul öncesi öğretmen adaylarının teknik donanımlarının ve teknolojik bilgilerinin artırılmasının bu alanda duydukları kaygıyı azaltabileceği düşünülmektedir. Bu doğrultuda okul öncesi öğretmen adaylarının eğitimine devam ettiği fakülte tarafından okul öncesi dönem çocuklarına uygun teknolojik araç gereç bilgisi ve kullanımını içeren dersler lisans müfredatlarına yerleştirilebilir. Okul öncesi öğretmen adaylarının teknik donanımlarının ve teknolojik bilgilerinin artırılması için herkesin erişebileceği online eğitimler düzenlenebilir. Eğitim fakültelerinin farklı uygulama derslerinde dersin sorumlu öğretim elemanı tarafından teknolojinin derse nasıl entegre edileceği öğretilebilir ve daha fazla teknoloji kullanımı özendirilebilir. Bu uygulamalarla bir yandan okul öncesi öğretmen adayının eğitimde teknoloji kullanımı konusunda daha donanımlı olacağı diğer yandan hissettiği kaygıyı azaltacağı düşünülmektedir.

\section{Yazarların Beyanı}

Araştırmacıların katkı oranı beyanı: Makalenin hazırlı aşamasına tüm yazarlar eşit oranda katkı vermiştir.

Etik Kurul Kararı: Kastamonu Üniversitesi, Sosyal ve Beşeri Bilimler Araştırma ve Yayın Etik Kurulu 25.03.2021 tarihli 2021/1 sayll kararı.

Çatışma beyanı: Araştırma süreci boyunca herhangi bir kişi veya kurumla çıkar çatışması yaşanmamıştır.

\section{Kaynaklar}

Avc1, Ö. H., Karababa, A., \& Zencir, T. (2019). Toplumsal cinsiyet bağlamında erkek okul öncesi öğretmen adayları: Algıladıkları güçlükler ve gelecek kaygıları. Hacettepe Üniversitesi Ĕ̆itim Fakültesi Dergisi, 34(4), 1092-1106.

Baturay, M. H., Gökçearslan, Ş., \& Ke, F. (2017). The relationship among pre-service teachers' computer competence, attitude towards computer-assisted education, and intention of technology acceptance. International Journal of Technology Enhanced Learning, 9(1), 1-13.

Beckers, J.J., Wicherts, J.M., \& Schmidt, H.G. (2007) 'Computer anxiety: 'trait' or 'state'?', Computers in Human Behavior, 23(6), 2851-2862.

Büyüköztürk, Ş. (2003). Sosyal bilimler için veri analizi el kitabı. Ankara: Pegem A Yayıncılık.

dos Reis, T. A. (2018). Study on the alpha generation and the reflections of its behavior in the organizational environment. Quest Journals Journal of Research in Humanities and Social Science, 6(1), 9-19.

Gümrükçü Bilgici, B., \& Deniz, Ü. (2016a). Okul öncesi öğretmen adaylarının mesleki kaygılarının bazı demografik özelliklere göre incelenmesi. Cumhuriyet International Journal of Education, 5(1), 53-70.

Gümrükçü Bilgici, B., \& Deniz, Ü. (2016b). Okul öncesi öğretmen adaylarının gelecek kaygılarının incelenmesi. Kastamonu Ĕ̆itim Dergisi, 24(5), 2353-2372.

Hardy, J. V. (1998). Teacher attitudes toward and knowledge of computer technology. Computers in the Schools, 14, 119-136.

Karasar, N. (2015). Bilimsel araştırma yöntemi: kavramlar, ilkeler, teknikler (28. Baskı). Ankara: Nobel.

Kılıç, S. (2013). Örnekleme yöntemleri. Journal of Mood Disorders, 3(1), 44-6.

Köklü, N., Büyüköztürk, Ş., \& Çokluk-Bökeoğlu, Ö. (2007). Sosyal bilimler için istatistik. Ankara: Pegem A Yayıncilık. 
Köknel, Ö. (2014). Kaygıdan korkuya. İstanbul: Remzi Yayınevi.

Kuzucu, Y. (2013). Kü̧̈ükler için büyüklere çocuk ve ergen ruh sağlığı. Ankara: Pegem.

Lei, J. (2009). Digital natives as preservice teachers: What technology preparation is needed?. Journal of Computing in teacher Education, 25(3), 87-97.

Magen-Nagar, N., \& Shonfeld, M. (2018). The impact of an online collaborative learning program on students' attitude towards technology. Interactive Learning Environments, 26(5), 621-637.

Millar, E., \& Walsh, M. (2000). Mental health matters in primary care. UK: Nelson Thornes.

Murati, R., \& Ceka, A. (2017). The use of technology in educational teaching. Journal of Education and Practice, 8(6), 197-199.

National Association for the Education of Young Children [NAEYC] (2012). Technology and interactive media as tools in early childhood programs serving children from birth through age 8. 20.04.2021 tarihinde https://www.naeyc.org/sites/default/files/ globallyshared/downloads/PDFs/resources/topics/PS_technology_WEB.pdf adresinden erişildi

Okur Akçay, N., \& Halmatov, M. (2015). Okulöncesi öğretmen adaylarının bilgisayar destekli eğitim yapmaya ilişkin tutumlarının incelenmesi. Trakya Üniversitesi Eğitim Fakültesi Dergisi, 5(1), 44-50.

Ömrüuzun, I. (2019). Okul öncesi öğretmenlerinin teknoloji kullanımlarını etkileyen faktörler: bir yol analizi çalışması (Yayımlanmamış yüksek lisans tezi). Hacettepe Üniversitesi, Ankara.

Polat, K., \& Karakuş, F. (2020). Öğretmen adaylarının bilgisayar destekli eğitime yönelik tutum ve öz yeterlik algılarının incelenmesi. Cumhuriyet Uluslararası Eğitim Dergisi, 9(2), 579-592.

Prensky, M. (2001). Digital natives, digital immigrants, Part 1. On the Horizon, 9(5), 1-6.

Revilla Munoz, O., Alpiste Penalba, F., Fernandez Sanchez, J., \& Santos, O. C. (2017). Reducing techno-anxiety in high school teachers by improving their ICT problem-solving skills. Behaviour \& Information Technology, $36(3), 255-268$.

Rosen, L., \& Weil, M. (1995). Computer availability, computer experience and technophobia among public school teachers. Computers in Human Behavior 11 (11): 9-31.

Ross, S. M., Morrison, G. R., \& Lowther, D. L. (2010). Educational technology research past and present: Balancing rigor and relevance to impact school learning. Contemporary Educational Technology, 1(1), 17-35.

Sancar Tokmak, H., Yavuz Konokman, G., \& Yanpar Yelken, T. (2013). Mersin Üniversitesi okul öncesi öğretmen adaylarının teknolojik pedagojik alan bilgisi (TPAB) özgüven algılarının incelenmesi. Ahi Evran Üniversitesi Kırşehir Ĕ̈itim Fakültesi Dergisi, 14(1), 35-51.

Schlebusch, C. L. (2018). Computer anxiety, computer self-efficacy and attitudes towards the Internet of first year students at a South African University of Technology. Africa Education Review, 15(3), 72-90.

Shillady, A., \& Parikh, M. (2012). New tools and strategies for teachers and learners. Young Children, 67(3), 1012.

Şahin, M. C., \& Namlı, N. A. (2019). Öğretmen adaylarının eğitimde teknoloji kullanma tutumlarının incelenmesi. Türkiye Sosyal Araştırmalar Dergisi, 23(1), 95-112.

Torkzadeh, G., \& Angulo, I. E. (1992). The concept and correlates of computer anxiety. Behaviour and Information Technology, 11(2): 99-108.

Turgut, K., \& Akdemir, E. (2019). Öğretmen adaylarının mobil öğrenmeye ilişkin tutumları. OPUS Uluslararası Toplum Araştırmaları Dergisi, 13(19), 500-526.

Türk Dil Kurumu [TDK] (2021). Türk Dil Kurumu sözlükleri. 15.02.2021 tarihinde https://sozluk.gov.tr adresinden erişildi. 
Uçar-Kaplan, E. (2015). Okul öncesi öğretmenlerinin yönetim ile yaşadığı sorunlar ve çözüm önerileri. Yaşadıkça Eğitim Dergisi, 29(1), 43-56.

Veloso, E. F.R., Dutra, J.S ., \& Nakata, L. E. (2016). Perception on intelligent careers: differences between generations and, and baby boomers. REGE-Revista de Gestão, 23(2), 88-98.

Yalçınalp, S., \& Cabı, E. (2015). Eğitim teknolojileri kullanımı kaygı ölçeği (ETKKÖ): ölçek geliştirme çalışması. Ilkogretim Online, 14(3), 1005-1016.

Yaşar Ekici, F., Türk, E. S., Asyalı, M., \& Kıroğlu, Z. (2018). Okul öncesi öğretmen adaylarının teknoloji kabul ve kullanım düzeyleri ile iletişim becerilerinin incelenmesi. H. Hülür ve S. Coşkun (Eds.) Sosyal, beşeri ve idari bilimler'de akademik araştırmalar - II içinde (s.125-149). Ankara: Gece Kitaplığı.

Yavuz Mumcu, H., \& Dönmez Usta, N. (2014). Öğretmen adaylarının bilgisayar ve internet kullanımına yönelik tutumları. Öğretim Teknolojileri ve Öğretmen Eğitimi Dergisi, 3(3), 44-55.

Zelyurt, H., \& Tuncer, M. (2016). Okul öncesi eğitimde öğretmen adaylarının bilgisayar destekli eğitime yönelik tutumlarının incelenmesi (Fırat ve İnönü Üniversiteleri Örneği). Turkish Journal of Educational Studies, 3(1), 1-21. 


\section{EXTENDED ABSTRACT}

\section{Introduction}

Nowadays, the use of technologies in education has been increasing exponentially through applications such as distance education, educational games and simulations (Ross, Morrison and Lowther, 2010). While it is a known fact that the role and importance of technologies in education are increasing day by day, this role has increased exponentially in the COVID-19 pandemic that has affected the almost whole world since the beginning of 2020. As the use of technologies in education changes, the role of teachers also changes. Factors such as student-centered approaches in which students are active learners, socialization with technologies, educational games, distance learning, and web communities may be reflections of this change process (Yalçınalp and Cabı, 2015). In this respect, it may be important to consider these factors in determining the anxiety level of teacher candidates about the use of educational technologies and the integration of technologies into education. In this study, it was aimed to investigate the anxiety of preschool teacher candidates about the use of technologies in education.

\section{Method}

To investigate preschool teacher candidates' anxieties about using technologies in education, a survey was conducted. Participants were 549 preschool teacher candidates who were educated in or graduated from preschool education departments of education faculties of various universities. General Information Form and Educational Technology Anxiety Scale developed by Yalçınalp and Cabı (2015) were used as data collection tools. The scale is 5-point Likert type, and consists of 5 sub-dimensions and 24 items. Five sub-dimensions are respectively; "Job Location-Centered Anxiety" (4 items), "Technology Disadvantage-Constraint-Centered Anxiety" (7 items), "Technology-Integration Centered Anxiety" (5 items), "Technology Management-Centered Anxiety" (5 items) and "Technique Centered Anxiety" (3 items).

\section{Results}

No statistically significant difference is observed between preschool teacher candidates' scores of subdimensions of educational technology anxiety scale according to gender. A similar situation exists between state universities and foundation universities. Namely, there is no statistically significant difference between preschool teacher candidates' scores of sub-dimensions of educational technology anxiety scale according to university type. On the other hand, the technology management-centered anxiety of graduate preschool teacher candidates is higher than the preschool teacher candidates who are studying in the first grade. The scores of technique centered anxiety of the graduate preschool teacher candidates are higher than the preschool teacher candidates who are studying in the first and second grade. Technology managementcentered and technique centered anxiety scores of preschool teacher candidates who have a personal computer are higher than those who do not have a personal computer. Finally, as the age of preschool teacher candidates increases, technology-integration-centered, technology-management-centered and technique centered concerns also increase.

\section{Conclusion}

In this study, which aims to investigate preschool teacher candidates' anxiety about using technologies in education according to various variables, it is seen that the most anxious sub-dimension for preschool teacher candidates is technique centered anxiety, and the least anxious sub-dimension is job location-centered anxiety. For preschool teacher candidates, the lack of competence in the use of technologies in teaching 36-72 monthold children and the fact that children have higher skills in technologies may have caused the technique centered anxiety to be the sub-dimension of the highest anxiety for preschool teacher candidates. On the other hand, it is clearly seen that the technological feasibility of the school, the existence of technological equipment in the school and the point of view of the school administration on the use of technologies will not cause anxiety for preschool teacher candidates. Therefore, it is understandable that job location-centered anxieties have the lowest anxiety sub-dimension.

In the literature, there are studies reporting that pre-school teacher candidates' perceptions of technological 
pedagogical content knowledge, self-confidence and their attitudes towards computer-assisted education do not change according to grade level (Sancar Tokmak, Yavuz Konokman, \& Yanpar Yelken, 2013; Okur Akçay \& Halmatov, 2015; Zelyurt \& Tuncer., 2016). On the other hand, studies stating that pre-school teacher candidates studying in the upper classes have a more positive attitude towards the use of technology in education than pre-service teachers in lower classes (Şahin \& Arslan Namll, 2018).

Preschool teacher candidates who have personal computers have higher technology management-centered and technique-centered anxiety than preschool teacher candidates who do not have a personal computer. It is thought that this situation is related to the awareness of preschool teacher candidates who have a personal computer about their competencies / inadequacies. Preschool teacher candidates who do not have a personal computer may not be aware of their competencies / inadequacies because they cannot use the necessary applications. 